\title{
Interdiffusing core-shell nanofiber interleaved composites for excellent Mode I and Mode II delamination resistance
}

Lode Daelemans $^{1}$, Nuray Kizildag ${ }^{1,2}$, Wim Van Paepegem ${ }^{1}$, Dagmar R. D'hooge ${ }^{1}$ and Karen De Clerck*1

${ }^{I}$ Department of Materials, Textiles and Chemical Engineering (MaTCh), Ghent University, TechnologieparkZwijnaarde 907/914, B-9052 Zwijnaarde, Belgium

${ }^{2}$ Integrated Manufacturing Technologies Research and Application Center, Sabanci University, Tuzla, 34956, Istanbul, Turkey

* Karen.DeClerck@UGent.be Tel.: +3292645740 Fax.: +3292645846

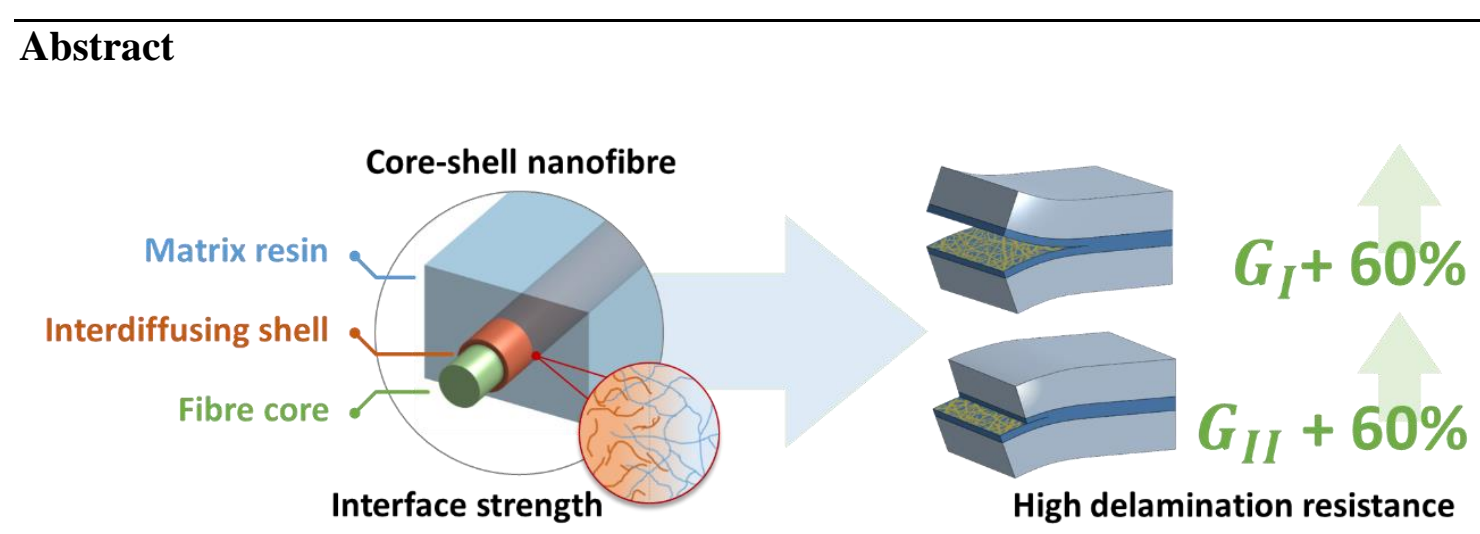

Electrospun nanofibre interleaving has a great potential for toughening of composite laminates as an effective, safe and industrially relevant method. Although many studies showcase large increases in delamination resistance, these are typically obtained under either Mode I or Mode II loading and for a wide variety of nanofibres. Here, we present a more general approach towards simultaneous excellent Mode I and Mode II delamination resistance using a single nanofibre system without the need for additional chemical modification steps or speciality polymers. It is illustrated based on the concept of interdiffusion of polycaprolactone nanofibres during the curing process into the epoxy matrix resin for improved adhesion. The results show that for a simultaneous increase in Mode I and Mode II delamination resistance, the adhesion and the fibre morphology of the nanofibres are crucial. The methodology is then expanded to allow for industrial relevant 
working windows by core-shell structured polyamide/polycaprolactone nanofibres. This approach results in a $G_{I C}$ of $650 \pm 50 \mathrm{~J} \mathrm{~m}-2\left(+\mathrm{ca} .60 \%\right.$ vs. virgin material) and a $G_{I I C}$ of $3160 \pm 35 \mathrm{~J}$ m-2 (+ ca. $60 \%$ vs. virgin material).

Keywords: A. Nano composites, B. Fibre/matrix bond, B. Interphase, B. Fracture toughness, E. Electro-spinning

\section{Introduction}

Electrospun polymer nanofibers are promising materials for improving the delamination resistance of composite laminates [1-3]. They can be directly deposited onto or interleaved as stand-alone veils between the reinforcing plies. Hence, they provide an easy way to introduce a tough phase in the resin-rich interlayers of composites without the need of dispersing toughening agent in the matrix material. In comparison with other nanotoughening technologies, they pose no health hazards. The polymer nanofibres are continuous in nature, have a relatively large diameter (typically between $50-500 \mathrm{~nm}$ ), come as a macroscopic non-woven membrane and can be made from non-toxic polymers. Thus in an industrial setting, there is almost no risk of airborne nanosized particles and the interaction between the operators and the nanofibres is limited. The presence of the nanofibres in the resin rich interlayers between plies has no detrimental effect on the inplane mechanical tensile and shear properties of the resulting laminates $[4,5]$.

Many nanofibre materials have already been tested for their toughening capability, e.g. polyamides ([2,6-13]), polyacrylonitrile ([14]), polycaprolactone (PCL) ([2,5,7,12]), polyvinylalcohol ([15]) and polyvinyl butyral ([12]). A recent review by Palazzetti and Zucchelli gives an excellent overview of the work performed in this research area [1]. Different toughening behaviours are observed depending on the nanofibre type (material 
properties) and delamination mode (interface properties), a point which has also been shown by Beckermann and Pickering [12]. In our previous work, we showed that the nanofibres toughen the composite by the formation of nanofibre bridging zones $[8,11,16]$. These zones are formed if a (micro)crack initiates in the nanotoughened interlayer. The nanofibres bridge the crack halves and need to be stretched before the crack can grow further. This typically requires a significant amount of energy due to the plasticity of the polymer nanofibres [16], resulting in an improved delamination resistance.

To obtain sufficient load transfer for straining the nanofibres, the adhesion between the matrix and the nanofibres needs to be sufficient [16]. It is however quite difficult to achieve good adhesion between the as-spun thermoplastic nanofibres and the (epoxy) matrix. Similar to sizing technology in traditional reinforcing fibres, dedicated chemical group modification can be applied to achieve better adhesion. For example, Bilge et al. introduced epoxide functional groups in their nanofibres that can covalently link with the epoxy polymer [17-20]. Although their results are promising, a dedicated chemical modification step was required.

In our previous work, we have put forward an elegant way to achieve promising adhesion between a nanofibrous phase and an epoxy matrix without the need of dedicated chemical modifications, which is based on interdiffusion at the interface of a thermoplastic polymer (PCL) and a resin phase (epoxy) cured at the appropriate temperature [21]. Controlled interdiffusion eventually creates a strong physical connection between both polymer phases through an interface consisting of interconnected macromolecules. This concept is general in nature and depends only on the capability of polymers to partially dissolve in each other. We showed that the adhesion is tunable depending on the processing conditions and 
improves the Mode I delamination resistance due to better load transfer to the nanofibres. However, an increased adhesion by interdiffusion also affects the fibre morphology and it is still unknown how this affects the delamination resistance under Mode II loading conditions. From our work on different interleaved morphologies [7], it is clear that the fibre morphology is a critical factor to achieve increased delamination resistance. In an ideal scenario, both Mode I as well as Mode II delamination resistance improve simultaneously to allow delamination resistant designs for practical applications.

In this contribution, we investigate the interaction between fibre morphology and nanofibre/matrix adhesion under Mode I as well as Mode II delamination conditions. Moreover, we extend our methodology [21] of interdiffusion for single component nanofibers, including temperature programs, to a multi-component system based on coaxial nanofibres with different core-to-shell (mass) ratios. The advantage of core-shell structured nanofibres is the freedom in choice of core and shell material, depending on the needs of the application. The shell provides adhesion to the matrix by interdiffusion, while the core provides the nanofibrous reinforcement at the microscale and can basically be any (functionalised) polymer. Moreover, coaxial electrospinning only differs from conventional electrospinning by using a coaxial nozzle with two material feeds instead of a single nozzle.

Here, polyamide 6 (PA6) / polycaprolactone (PCL) coaxial nanofibres are used to enhance the delamination resistance of glass fibre reinforced composite laminates. PA6 is selected as a highly relevant core material as it can potentially result in very high increases of the delamination resistance but is known to result in limited toughness in practice due to limited adhesion with the epoxy matrix [16]. Coaxial nanofibres are produced with different core-to-shell ratios to analyse different degrees of interdiffusion and thus 
adhesion. Interleaved glass fibre composites are produced with the set of coaxial nanofibres and tested for their delamination resistance under both Mode I and Mode II loading conditions. The results reveal new insights into the balance between adhesion and fibre morphology and allow for the design of novel nanofibre systems for toughening based on interdiffusion.

\section{Experimental}

\subsection{Materials}

Polyamide 6 (Sigma Aldrich, $\mathrm{M}_{\mathrm{w}} 51000 \mathrm{~g} \mathrm{~mol}^{-1}$ ), polycaprolactone (Sigma Aldrich, $\mathrm{M}_{\mathrm{n}}$ $80000 \mathrm{~g} \mathrm{~mol}^{-1}$ ), formic acid (Sigma Aldrich, 98\%), and acetic acid (Sigma Aldrich, 98\%) were used as received in the electrospinning solutions. Epoxy resin (EPIKOTE MGS RIMR135) and hardener (EPIKURE MGS RIMH137) were supplied by Momentive. Both products were used as received. All composite laminates were reinforced with unidirectional E-glass fabrics (SGL Group, UDO ES500, $500 \mathrm{~g} \mathrm{~m}^{-2}$ ).

\subsection{Methods}

\subsubsection{Electrospinning of single component and multi-component (coaxial)} nanofibres

For the electrospinning of single component PA6 and PCL nanofibres, a 1/1 (volume based) formic acid (FA)/acetic acid (AA) solvent system was selected based on previous studies $[22,23]$. The same solvent system was used to produce coaxial PA6/PCL nanofibres. The required amounts of polymer were added to the solvent mixtures and mixed at room temperature using a magnetic stirrer until a clear solution was obtained. For the production of PA6/PCL core-shell structured nanofibers, a coaxial needle (Raméhart 
Custom Needle, 100-10-COAXIAL-2016, outer needle: $1.7 \mathrm{~mm}$ OD, inner needle: $0.9 \mathrm{~mm}$ OD) was used. Two syringe pumps (KD Scientific Pump Series 100) were used to feed the core and shell solutions, respectively. A high voltage power supply (Glassman High Voltage Series) was used to apply a voltage to the outer needle. The tip to collector distance (TCD), the flow rates (FR) of the solutions and the voltage were adjusted to obtain stable electrospinning and uniform coaxial nanofibers. Table 1 reports the solution and electrospinning parameters for the nanofibers used in this work. Uniform deposition of the nanofibers was ensured using an in-house developed electrospinning machine with a linear translating nozzle support and a perpendicular linear translating collector (Figure 1a). The nanofibres were directly electrospun onto the glass fibre plies at an areal density of $5 \mathrm{~g} \mathrm{~m}^{-2}$ using a single electrospinning nozzle The nanofibre areal density of the deposited nanofibres was measured after every $300 \mathrm{~mm}$ of electrospinning (moving collector) by precisely cutting out $75 \times 75 \mathrm{~mm}^{2}$ squares and measuring the mass of nanofibres deposited. All specimens were obtained within the range of $5 \pm 0.3 \mathrm{~g} \mathrm{~m}^{-2}$.

To validate the core-shell fibre morphology, specimens of the coaxial nanofibers taken at different sections of the veils were immersed into $10 \mathrm{~mL}$ of anisole to extract the PCL shell (anisole does not dissolve PA6). Each specimen underwent three anisole treatments before being rinsed and dried at room temperature. Representative SEM images of coaxial nanofibers taken before and after anisole treatment are shown in Figure 1b. It follows that the coaxial nanofibers were uniform in structure and had smooth surfaces. The continuous fibre structure is thus preserved after PCL extraction, confirming that the coaxial nanofibres have a homogeneous and continuous PA6 core and PCL shell fibre morphology. 
Table 1 - Electrospinning parameters to obtain coaxial nanofibres with a range of core-toshell ratios (TCD: tip-to-collector distance; FR: flow rate)

\begin{tabular}{|c|c|c|c|c|c|c|}
\hline Name & $\begin{array}{c}\text { Core-to- } \\
\text { shell } \\
\text { ratio }^{1}\end{array}$ & $\begin{array}{l}\text { Electrospinning } \\
\text { solutions }\end{array}$ & $\begin{array}{l}\text { TCD } \\
(\mathbf{c m})\end{array}$ & $\begin{array}{c}\text { FR } \\
\text { Core } \\
(\mathbf{m l} / \mathbf{h})\end{array}$ & $\begin{array}{c}\text { FR } \\
\text { Shell } \\
(\mathbf{m l} / \mathbf{h})\end{array}$ & $\begin{array}{c}\text { Voltage } \\
(\mathbf{k V})\end{array}$ \\
\hline 100:0 PA6/PCL & 100:0 & $18 \mathrm{wt} \%$ PA6 & 6 & 1.5 & - & 25 \\
\hline 90:10 PA6/PCL & $90.5: 9.5$ & $\begin{array}{l}18 \mathrm{wt} \% \text { PA6 } \\
8 \mathrm{wt} \% \text { PCL }\end{array}$ & 8 & 1.5 & 0.4 & 30 \\
\hline 70:30 PA6/PCL & $73.0: 27.0$ & $\begin{array}{l}18 w t \% \text { PA6 } \\
8 w t \% \text { PCL }\end{array}$ & 8 & 1.5 & 1.4 & $30-35$ \\
\hline 50:50 PA6/PCL & $52.4: 47.6$ & $\begin{array}{l}18 \mathrm{wt} \% \text { PA6 } \\
13 \mathrm{wt} \% \text { PCL }\end{array}$ & 10 & 0.6 & 0.8 & 25 \\
\hline 0:100 PA6/PCL & $0: 100$ & $14 \mathrm{wt} \% \mathrm{PCL}$ & 15 & - & 1.5 & 35 \\
\hline \multicolumn{7}{|c|}{${ }^{1}$ Determined by the flow rates and concentrations of both solutions and validated by } \\
\hline
\end{tabular}




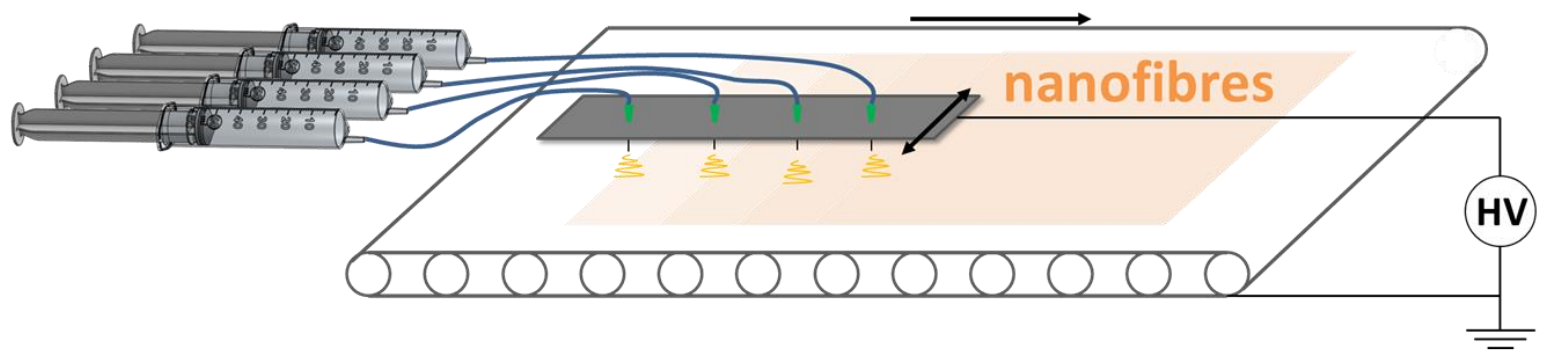

(a)
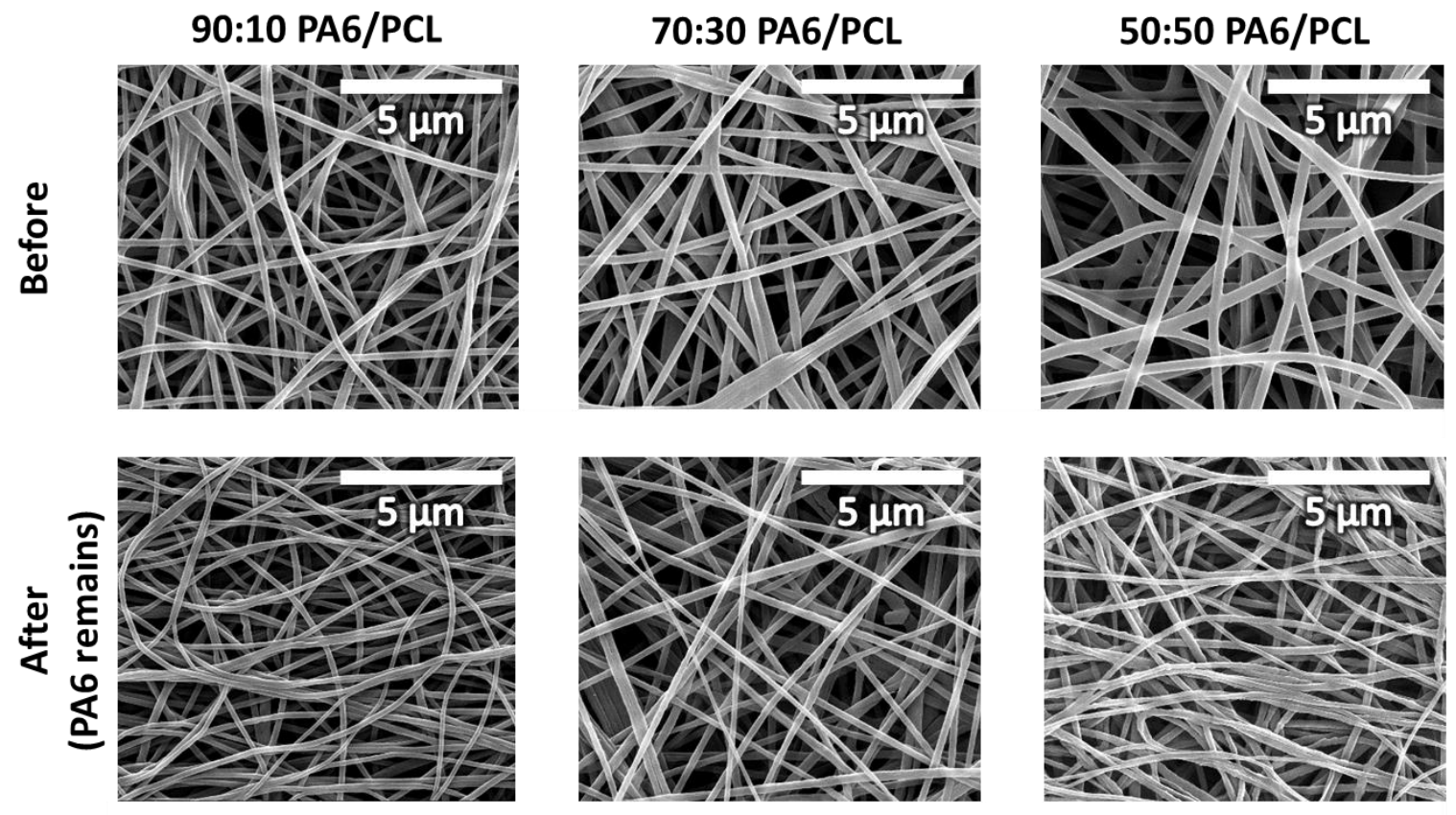

(b)

Figure 1 - (a) Schematic overview of our in-house developed electrospinning setup

(four nozzles are shown). (b) Representative SEM images of the coaxial PA6/PCL

nanofibres before and after anisole treatment (dissolves only PCL) show that high-quality

core-shell structured nanofibers are obtained.

\subsubsection{Production and characterization of nanofiber interleaved composite} laminates 
Nanofiber interleaved composite laminates were made using an in-house developed vacuum assisted resin transfer moulding (VARTM) setup, which consists of a two-piece flat steel mould with inner dimensions of $300 \times 300 \times 3 \mathrm{~mm}^{3}$. The glass fibre mats were cut to $300 \times 300 \mathrm{~mm}^{2}$ and stacked into the steel mould in a $\left[0^{\circ}\right]_{8}$ configuration. The two middle plies had nanofibres directly deposited on the side facing the midplane, resulting in a total of $10 \mathrm{~g} \mathrm{~m}^{-2}$ of nanofibers in the interlayer (nanofibre interlayer thickness was $43 \pm 10 \mu \mathrm{m}$ ). An ethylene tetrafluoroethylene-based release film was placed in the midplane of the stacking to serve as an initial delamination in the delamination experiments. Reference specimens without nanofibres were produced in the same manner. Prior to infusion, the epoxy resin (EPIKOTE MGS RIMR135) and hardener (EPIKURE MGS RIMH137) were mixed in a 10:3 mass ratio using a mechanical stirrer and degassed under vacuum for 15 min. After the infusion, the mould was cured at a fixed temperature in an oven to allow full conversion of the resin at the selected temperature (based on differential scanning calorimetry data obtained on the resin system, see Table S1 in Supplementary Information).

Specimens with nominal dimensions of $150 \times 20 \times 3 \mathrm{~mm}^{3}$ were cut from the cured laminates using a water-cooled diamond saw. The Mode I and Mode II interlaminar fracture toughness (delamination resistance) were determined using the Double Cantilever Beam (DCB) and End Notched Flexure (ENF) method respectively. A picture of the test specimens and setup is given in Figure S1 in Supplementary Information. The Mode I interlaminar fracture toughness $G_{I C}$ was calculated according to the ASTM D5528 method:

$$
G_{I c}=\frac{3 P \delta}{2 b(a+|\Delta|)} F
$$


where $P$ is the critical load, $\delta$ is the critical displacement, $b$ is the width, $a$ is the delamination length, $\Delta$ corrects for crack front rotations, and $F$ corrects for large displacement effects (for piano hinges). The $G_{I c}$ value was determined from the loaddisplacement curves at the $5 \% /$ max point according to the procedures outlined in the ASTM standard. A natural Mode I pre-crack was first produced in the specimens by loading them to crack initiation after which they were immediately unloaded. The delamination test was performed at $3 \mathrm{~mm} \mathrm{~min}^{-1}$ and the delamination growth was monitored using a traveling microscope. The Mode II interlaminar fracture toughness $G_{I I C}$ was calculated using the Compliance Based Beam Method [24]:

$$
G_{I I c}=\frac{9 P^{2} a_{e q}^{2}}{2 E_{f} b^{2}(2 h)^{3}}[1-\zeta]
$$

where $P$ is the critical load (maximum load encountered during the test), $a_{e q}$ is the corrected delamination length, $E_{f}$ is the flexural modulus, $b$ is the width, $2 h$ is the specimen thickness, and $[1-\zeta]$ corrects for large displacement effects. An initial delamination length of $37.5 \mathrm{~mm}$ and a span of $100 \mathrm{~mm}$ resulted in stable crack growth conditions. The specimens were loaded under three point bending at $1 \mathrm{~mm} \mathrm{~min}^{-1}$. An Instron 3369 equipped with a $500 \mathrm{~N}$ and $2000 \mathrm{~N}$ load cell was used to perform the DCB tests and the ENF test respectively. The fracture surface of the delaminated specimens was investigated by optical and scanning electron microscopy (Jeol Quanta 200 FESEM). 


\section{Results and Discussion}

\subsection{The relation between curing temperature and Mode I and Mode II delamination resistance for single component interdiffusing nanofibres}

Figure 2 shows $G_{I C}$ and $G_{I I C}$ obtained for composites interleaved with single component PCL nanofibrous veils and cured at temperatures between $30^{\circ} \mathrm{C}$ and $80^{\circ} \mathrm{C}$ (until final conversion at the selected temperature). For non-modified virgin laminates, no effect of the curing temperature on $G_{I C}$ and $G_{I I C}$ is found and they are represented by a single averaged value instead. For both delamination modes, the nanofibre interleaved specimens show a clear, but opposite, trend in delamination resistance as a function of the curing temperature. While $G_{I C}$ tends to increase, $G_{I I C}$ decreases for increasing curing temperatures.

Our previous work [21] showed that the interdiffusion of PCL polymer chains into the epoxy matrix results in a stronger PCL/epoxy interface, as conceptually shown in Figure 3 and covering the results in Figure 2. An analytical diffusion model was constructed that allowed determination of the molar flux of PCL polymer at the interface during conversion of the epoxy resin. Higher molar fluxes of PCL, attained at higher isothermal curing conditions due to the higher mobility of the polymer chains, improved the adhesion of the PCL phase with the epoxy phase. This resulted in higher Mode I delamination resistance of PCL nanofibre interleaved laminates as a more efficient nanofibre bridging zone can develop with less nanofibre debonding occurring [21] (Figure 2, left). 
Mode I delamination
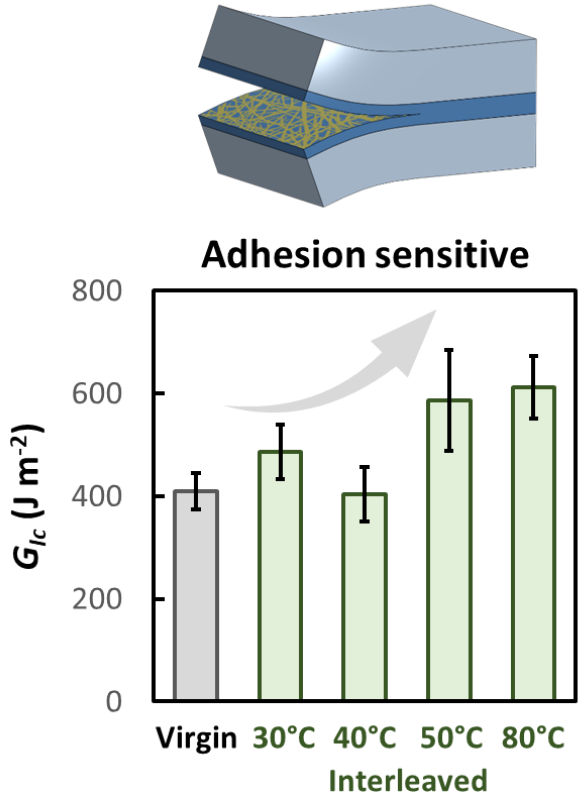

Mode II delamination

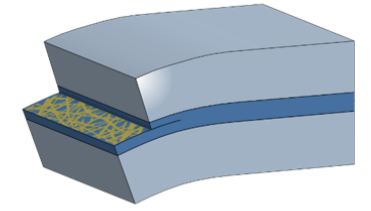

Fibre morphology sensitive

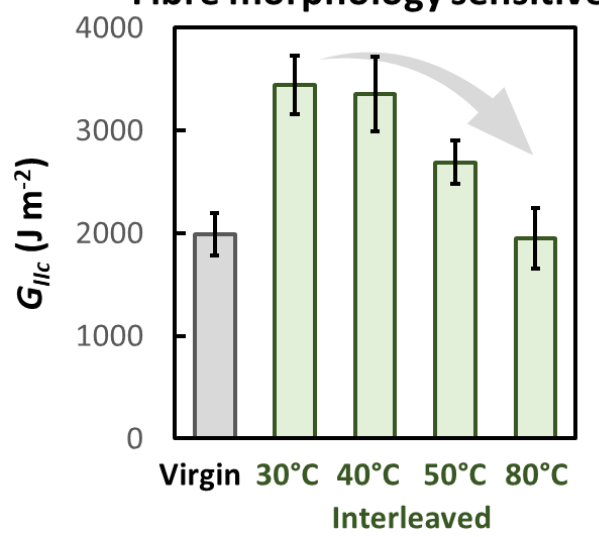

Figure 2 - The Mode I (left) and Mode II (right) delamination resistance show an opposite trend for higher curing temperatures (more interdiffusion at the interface) of the composites based on single component nanofibres. While $\mathrm{G}_{\mathrm{Ic}}$ increased with higher temperature due to better nanofibre/matrix adhesion, $\mathrm{G}_{\mathrm{IIC}}$ decreases due to a loss of the fibre morphology.

Higher isothermal curing temperatures however drastically affect the fibre morphology of the PCL nanofibres as high amounts of interdiffusion result in the dissolution of the nanofibers, taking into account their small dimensions [25]. While this does not seem problematic for $G_{I C}$, the decreasing trend in $G_{I I C}$ in Figure 2 clearly shows the sensitivity of the Mode II delamination resistance for the fibre morphology. Indeed, curing temperatures of $30^{\circ} \mathrm{C}$ and $40^{\circ} \mathrm{C}$, which hardly affect the nanofibres by interdiffusion, result in extreme improvements of $G_{I I C}$ up to $75 \%$. On the other hand, higher curing temperatures of $50^{\circ} \mathrm{C}$ and $80^{\circ} \mathrm{C}$ result in much lower improvements of $G_{I I C}$ due to a loss of the fibre morphology. 


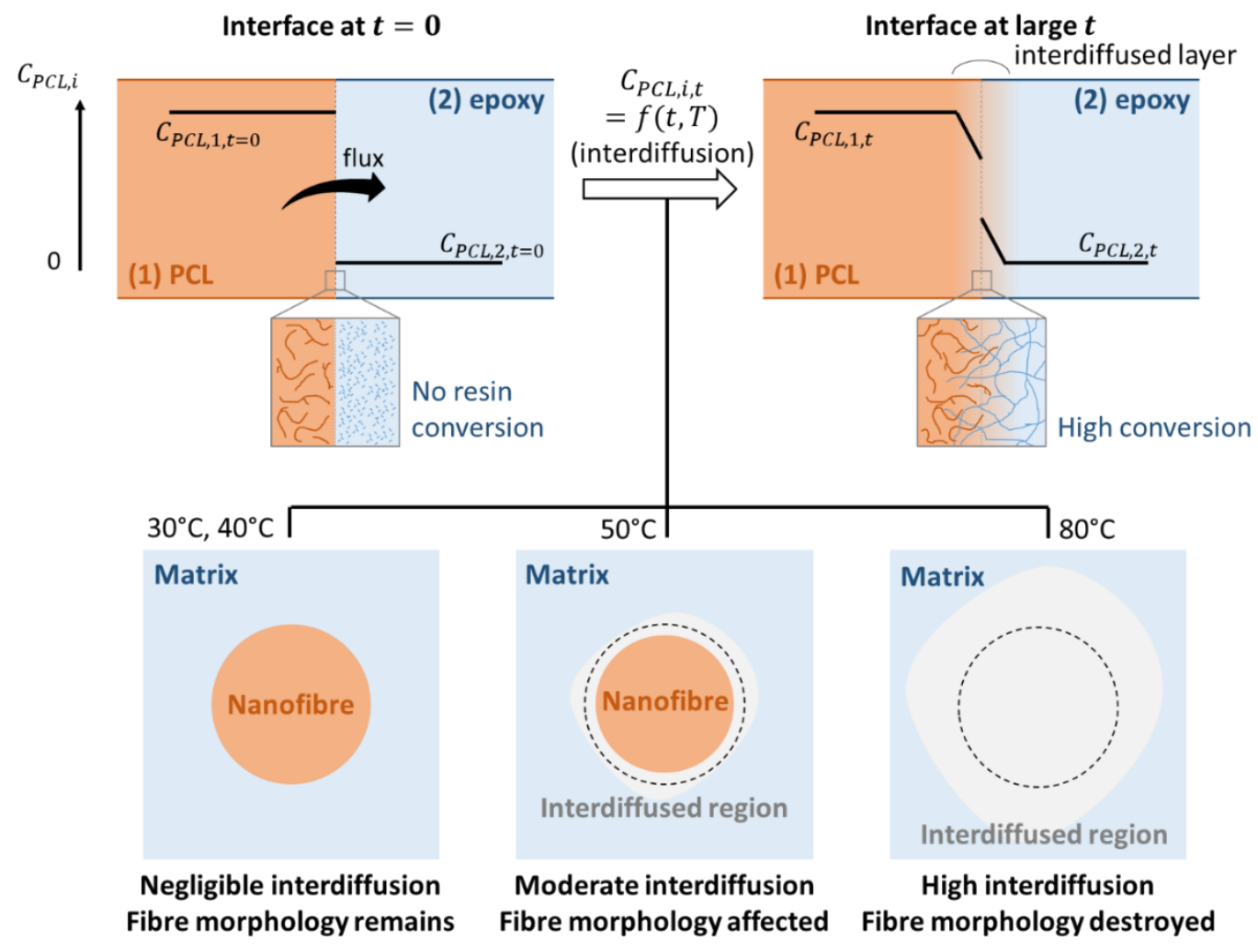

Figure 3 - The concept of interface formation due to interdiffusion in single component nanofibre interleaved composites as introduced in [21]. During isothermal conversion of the epoxy resin, PCL polymer chains can diffuse into the epoxy component. Depending on the curing temperature (and the correlated curing time), this can result in negligible interdiffusion at low temperatures, moderate interdiffusion at moderate temperatures, and complete dissolution of the nanofibres at high curing temperatures. Increased interdiffusion however also leads to a loss in fibre morphology which is detrimental for $G_{I I c}$.

Analysis of the fracture surface of delaminated specimens confirms the trade-off between good adhesion and fibre morphology for single component nanofibres (Figure 4). Only a moderate curing temperature of $50^{\circ} \mathrm{C}$ results in improved bonding while still maintaining the fibre morphology. Higher curing temperatures result in the complete dissolution of the nanofibrous structure, and in the case of PCL, a finely dispersed phase-separated structure. 
Lower curing temperatures, on the other hand, maintain the nanofibrous structure but show no signs of good nanofibre/matrix adhesion. Hence, the conceptual trends in Figure 3 are confirmed by SEM analysis.

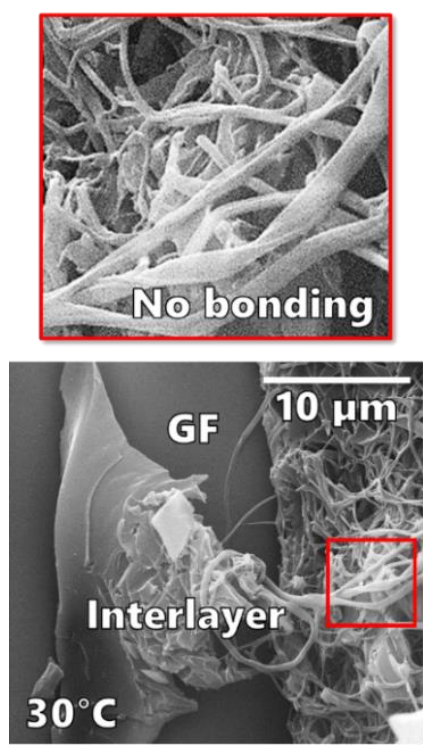

(a)

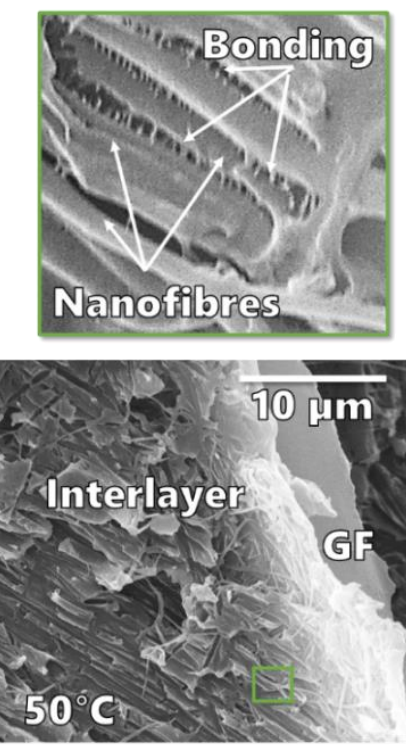

(b)

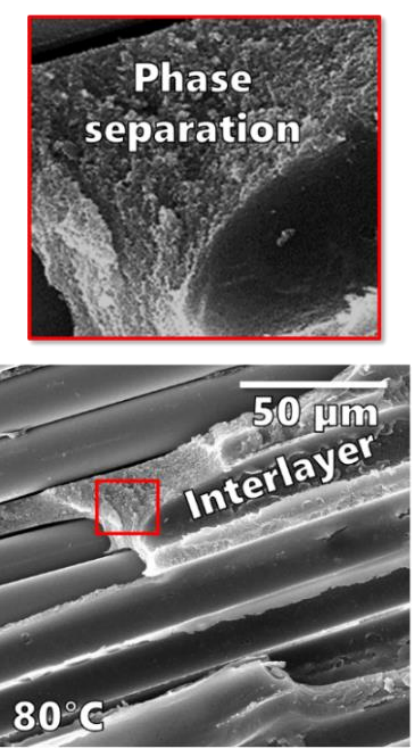

(c)

Figure 4 - SEM analysis of the fracture surface of delaminated specimens (single component nanofibres) cured at (a) $30^{\circ} \mathrm{C}$, (b) $50^{\circ} \mathrm{C}$ and (c) $80^{\circ} \mathrm{C}$ shows that only moderate curing temperatures result in an interlayer in which the fibre morphology is still intact and good bonding between the nanofibres and the matrix is visible consistent with the conceptual results in Figure 3.

As such there is a fundamental constraint using interdiffusing nanofibres: creating better adhesion by higher interdiffusion also destroys the fibrous morphology. Yet our results demonstrate that both aspects are crucial for simultaneous increases in Mode I and Mode II delamination resistance for a certain nanofibre system. Moreover, retaining the fibre morphology also opens up other use-cases alongside toughening such as sensors based on dedicated nanofibre systems [26,27]. This thus limits the general applicability of such 
nanofibres as they will only perform in a small range of curing temperatures, which is likely to be incompatible with the working window in specific applications. Expansion of this concept to a wider applicable system is done in the following subsections.

\subsection{The relevance of a step-wise temperature curing profile for single component nanofibres}

A first curing step at low temperature results in the partial conversion of the epoxy resin, therefore increasing its viscosity, without much interdiffusion occurring. After this step, the partially cured epoxy forms a self-sustaining mould that will retain the fibre morphology of the nanofibres. A second curing step at a high temperature then provides sufficient interdiffusion to occur for good adhesion, while opening up the possibility of higher temperature curing (Figure 5a). This concept of using a step-wise curing cycle to allow for sufficient interdiffusion while retaining the fibre morphology at high curing temperatures has already shown its usefulness in our previous work on PCL nanofibres [3,5,7,16,21].

To confirm if the same adhesion versus fibre morphology principle is valid in these structures, two curing profiles are considered, i.e. (i) full cure at $40^{\circ} \mathrm{C}$ for 50 hours, followed by post-cure at $80^{\circ} \mathrm{C}$ for 15 hours (Cycle 1); and (ii) partial cure at room temperature for 24 hours, followed by post-cure at $80^{\circ} \mathrm{C}$ for 15 hours (Cycle 2). While Cycle 1 does not allow sufficient interdiffusion for adhesion and thus a low $G_{I c}$ improvement is obtained, Cycle 2 provides sufficient interdiffusion, resulting in a high $G_{I C}$ improvement [21]. Both step-wise curing cycles retain the fibre morphology, even though the specimens are post-cured at $80^{\circ} \mathrm{C}$ which is above the PCL melting temperature $\left(T_{m} \approx 55^{\circ} \mathrm{C}\right)$ (confirmed by SEM analysis, not shown here). 
Again, delamination experiments support that the improvement in $G_{I C}$ is determined by the nanofibre/matrix adhesion, while the improvement in $G_{I I c}$ is determined by the fibre morphology of the nanofibres (Figure 5b). Indeed, only Cycle 2 results in $G_{I C}$ improvement since it allows sufficient interdiffusion, while both Cycle 1 and Cycle 2 result in $G_{I I c}$ improvement as the fibre morphology is retained.

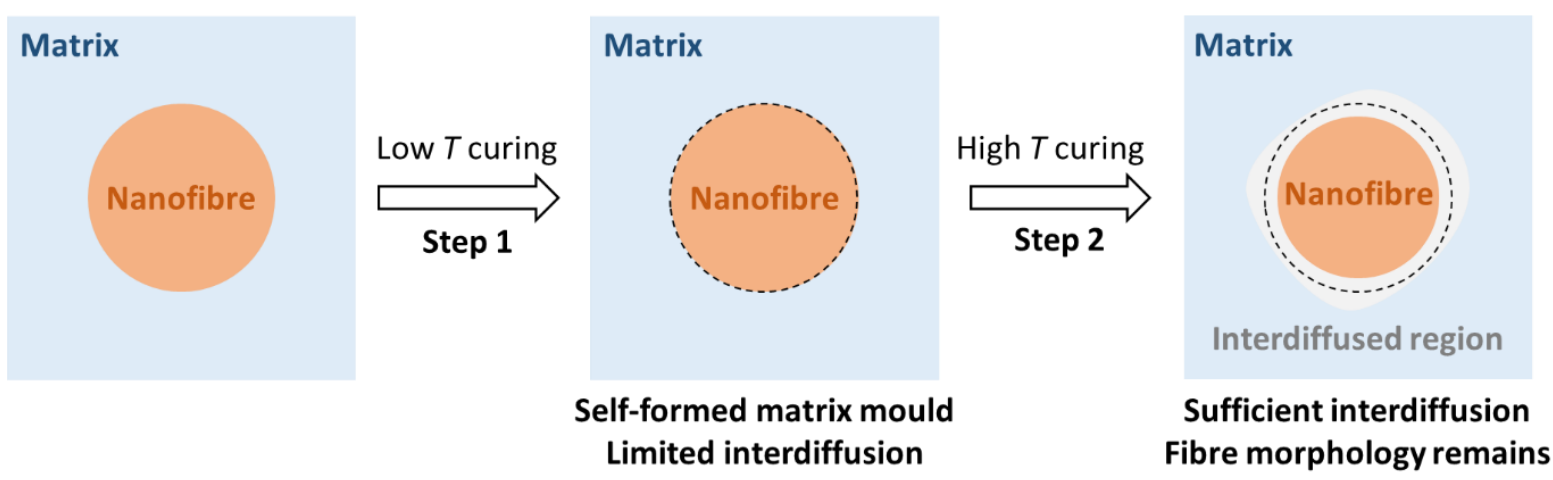

(a)

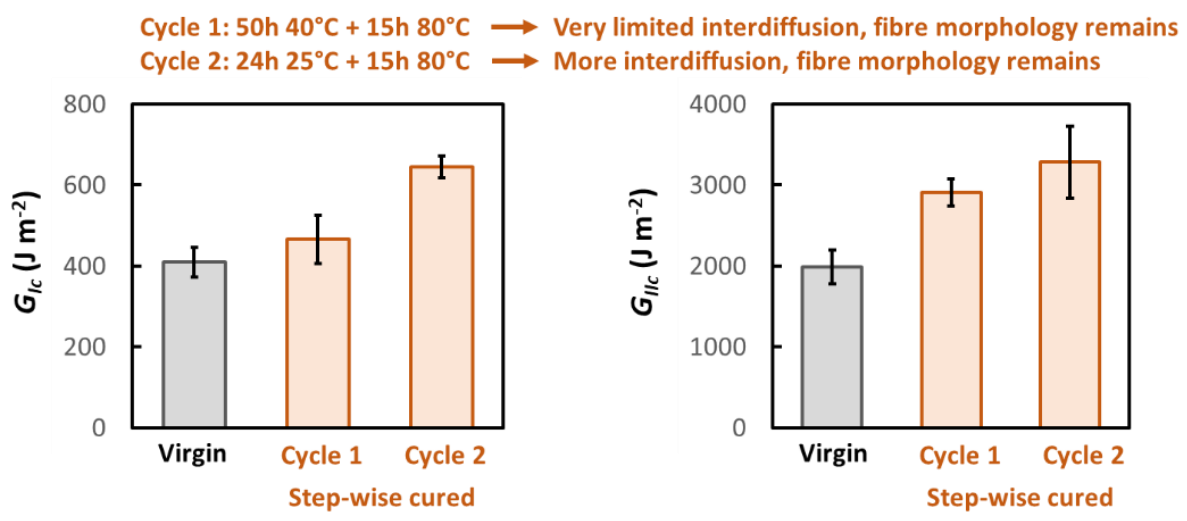

(b)

Figure 5 - (a) Concept of using two curing steps to retain the fibre morphology at step 1 while allowing for interdiffusion to take place at step 2 for single component nanofibres.

(b) Delamination experiments show that a high improvement in $G_{I C}$ and $G_{I I c}$ can be obtained simultaneously for a well-chosen curing cycle (b). 
Although the use of step-wise curing cycles allows for a better optimum between the nanofibre/matrix adhesion and retention of the fibre morphology, it is again limited in its general applicability. For many composite applications, the curing cycles are fixed and an initial low temperature curing step for long time is not acceptable. The potential of the interdiffusion capability of PCL nanofibers could be enhanced if there was a better, oneshot manner of allowing good interdiffusion while retaining the nanofibrous nature of the materials. Such manner is explored in the next subsection.

\subsection{Core-shell structured nanofibres with an interdiffusing shell to enable better performance under both delamination modes}

The use of core-shell structured nanofibres with an interdiffusing shell allows for improving the adhesion of nanofibres whose use is limited under normal circumstances due to an insufficient bonding with the matrix resin (Figure 6a). Furthermore, by selecting a more temperature resistant core polymer than PCL, such nanofibres allow faster curing cycles at elevated temperatures without the need for a prolonged low temperature initial curing step. This concept thus has the potential to be generally applicable to a wide range of applications.

In our earlier work, PA6 interleaved composites provided very good improvements in $G_{I I c}$, but never resulted in an improved $G_{I C}$ as they were prone to debonding under Mode I loading [16]. Here, PA6-PCL core-shell structured nanofibres are proposed to obtain both good adhesion by interdiffusing of the PCL shell, while retaining the fibre morphology using a PA6 core which is not affected by interdiffusion at curing temperatures of $80^{\circ} \mathrm{C}$ $\left(T_{m, P A 6} \approx 220^{\circ} \mathrm{C}\right)$. A direct cure at $80^{\circ} \mathrm{C}$ is used to allow for immediate interdiffusion. 
It is clear that there is a synergistic effect for the coaxial nanofibre interleaved laminates which all have simultaneous improvements in both $G_{I c}$ and $G_{I I c}$ (Figure 6b). The PCL shell thus indeed provides sufficient adhesion with the epoxy matrix due to the interdiffusion effect. Combined with a nanofibrous core, this result in improvements of the delamination resistance under Mode I as well as Mode II loading.
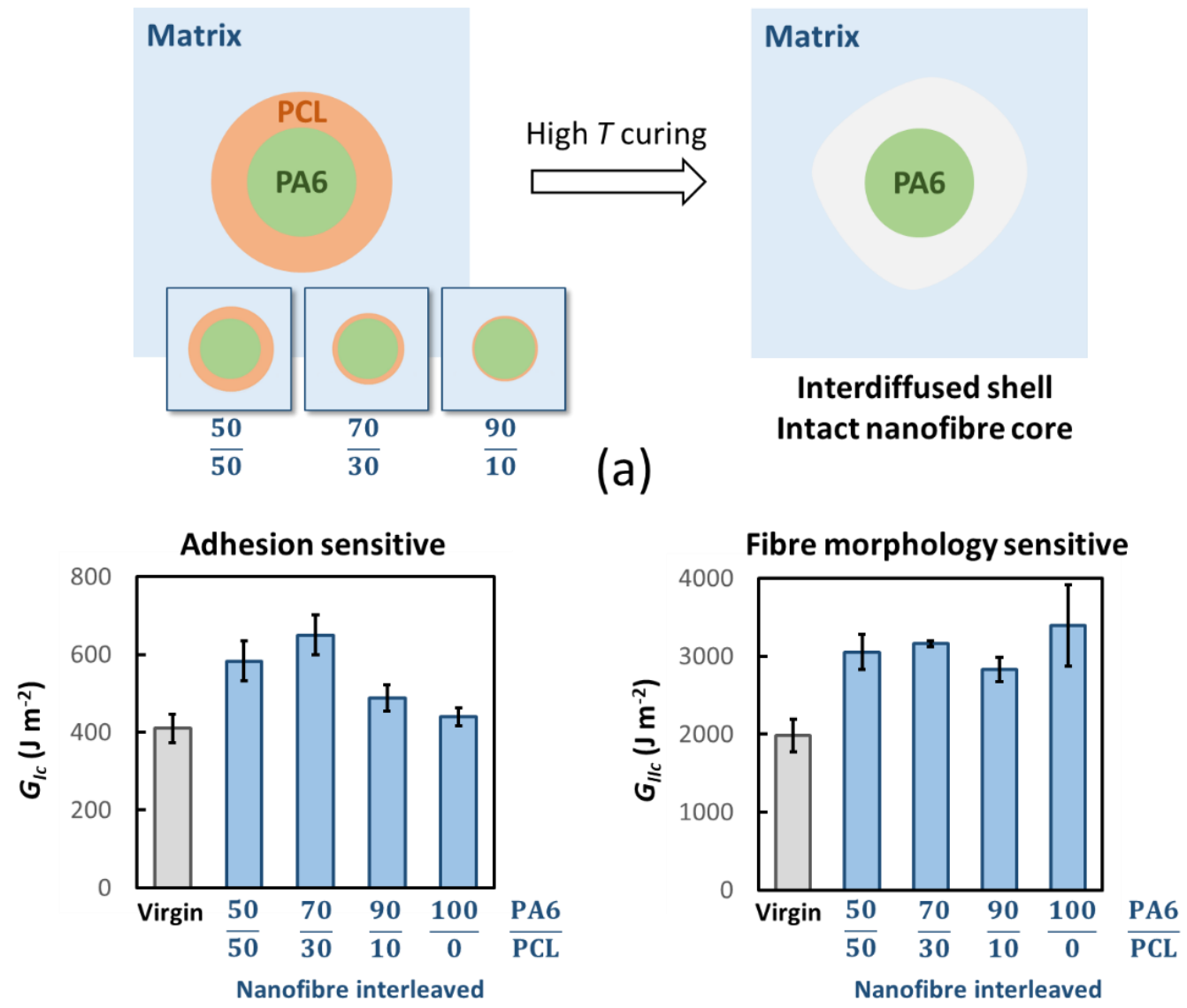

(b)

Figure 6 - Concept of using core-shell structured PA6/PCL multicomponent nanofibres with different core-to-shell ratios to obtain good adhesion with the matrix without a loss of the nanofibrous structure (a). Optimum adhesion is obtained for the core-to-shell ratio of 70:30 resulting in the highest increase in $G_{I C}$, while the improvement in $G_{I I c}$ remains similar for all ratios as the PA6 cores had a similar diameter and fibre morphology (b). 
The results of the coaxial nanofibre interleaved laminate indicate a dependency of the delamination resistance on the core-to-shell ratio. Note that the electrospinning was optimized to form coaxial nanofibres in which the PA6 core always had a similar (average) diameter of around $200 \mathrm{~nm}$, similar to the diameter of pure PA6 nanofibres (Table 2). The results show that the increase in $G_{I I C}$ is due to the remaining PA6 nanofibrous cores in the epoxy resin without much effect of interdiffusing PCL shell. Indeed, the increase in $G_{I I c}$ remains similar for all tested core-to-shell ratios, as well as pure PA6 nanofibres.

On the other hand, the increase in $G_{I c}$ is dependent on the core-to-shell ratio and thus the adhesion between the PA6 core and the matrix resin. An optimum PA6:PCL ratio of 70:30 is found to result in the highest Mode I delamination resistance. This indicates that higher core-to-shell ratios likely result in less interdiffusion and thus a less efficient bonding of the PA6 core to the matrix resin, resulting in only moderate improvements of $G_{I c}$. Lower coreto-shell ratios result in a higher PCL fraction that can interdiffuse, resulting in better adhesion. However, the data in Figure $6 \mathrm{~b}$ shows that there is a limit to this mechanism since a core-to-shell ratio of 50:50 performs less than a ratio of 70:30.

Table 2: The diameter of the PA6 core that remains in the composites is around $200 \mathrm{~nm}$ for each of the core-to-shell ratio nanofibres used in Figure $6 \mathrm{~b}$.

\begin{tabular}{lcc}
\hline Core-to-shell mass ${ }^{\mathbf{1}}$ ratio & Nanofibre diameter (nm) & Core diameter (nm) \\
\hline $100 / 0$ & $195 \pm 35$ & $195 \pm 35$ \\
$90 / 10$ & $205 \pm 20$ & $190 \pm 25$ \\
$70 / 30$ & $235 \pm 30$ & $195 \pm 45$ \\
$50 / 50$ & $285 \pm 35$ & $200 \pm 50$ \\
${ }^{1}$ Note that the mass ratio is similar to the volume ratio as the densities of both polymers are \\
similar.
\end{tabular}



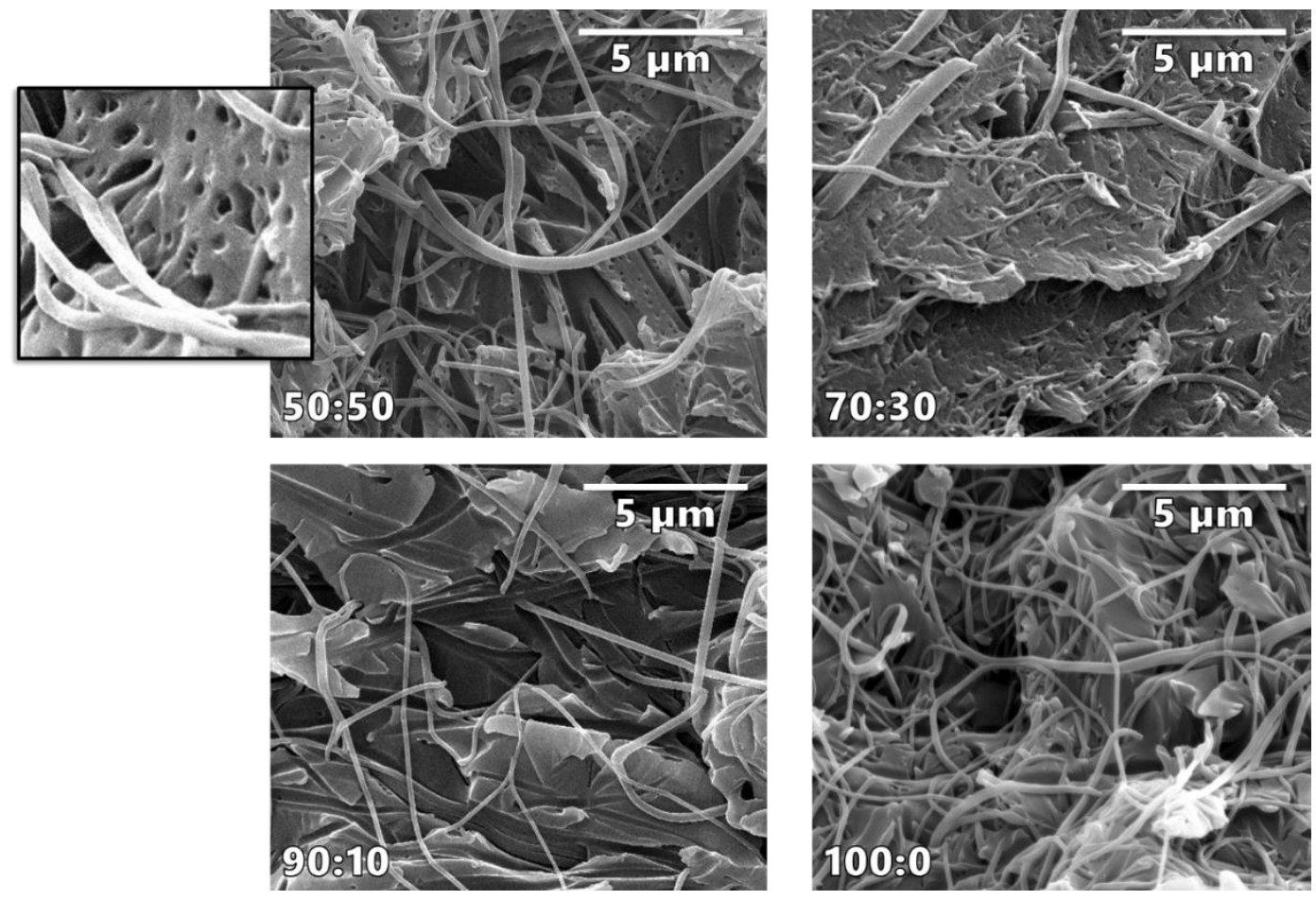

Figure 7 - SEM analysis of Mode I delaminated specimens reveals different interlayer morphologies depending on the core-to-shell ratio (PA6:PCL) of the interleaved multicomponent nanofibres. An additional phase separated microstructure between the nanofibres is obtained for low core-to-shell ratios (top left, 50:50). The optimal ratio is 70:30 (see also Figure 6).

Analysis of the fracture surface of the Mode I delaminated specimens shows different interlayer morphologies depending on the core-to-shell ratio (Figure 7). For a 50:50 PA6:PCL ratio, a complex interlayer morphology is obtained with a moderate amount of peeled nanofibres with a phase-separated structure of epoxy and PCL in between. This phase separated structure can be the cause for the lower improvement in $G_{I c}$. For a 70:30 PA6:PCL ratio, good adhesion is observed with almost no peeled nanofibres visible. The nanofibres clearly failed in a tensile mode, indicating good adhesion with the matrix. For the 90:10 PA6:PCL ratio, a relatively large amount of peeled nanofibres is visible together 
with their imprints in the epoxy matrix indicating a lack of adhesion. For pure PA6 nanofibres, almost no adhesion with the matrix is visible and the fracture surface is fully occupied with peeled nanofibres. These observations coincide with the improvements in $G_{I C}$, where a core-to-shell ratio of 70:30 PA6:PCL resulted in the best improvements and thus the best improvement in adhesion.

The overview in delamination resistance improvements for different nanofibre systems mentioned in literature, as given by Palazzetti and Zucchelli in [1], shows that the coaxial nanofibres are among the top performing systems currently available. Hence, coaxial nanofibres - with correct control of the size of the core and shell - are a viable option for designing a generally applicable nanofibre system for improved delamination resistance of composite structures under both modes.

\section{Conclusions}

Composites interleaved with nanofibres capable of interdiffusion with the epoxy matrix have been successfully produced for their Mode I and Mode II delamination resistance. The improved Mode I delamination resistance is determined by the adhesion between the nanofibrous phase and the matrix, but less by the fibrous morphology of the nanofibres. Improved Mode II delamination resistance, on the other hand, is determined by the fibre morphology of the nanofibrous phase. A clear and well-defined fibre morphology results in high improvements, while the adhesion does not seem to have a significant effect.

Due to the interplay between adhesion and fibre morphology in interdiffusing nanofibres, single component systems have a very narrow working range in which Mode I, as well as Mode II delamination resistance, are improved simultaneously. The use of two curing 
temperatures resolves this issue but still, the general applicability is less. Interestingly, coaxial structured nanofibres provide the means to allow sufficient interdiffusion from the shell polymer, while maintaining a clear fibre morphology from the core polymer, resulting simultaneously in high Mode I and Mode II delamination resistance. The core-to-shell ratio affects the Mode I delamination resistance due to different amounts of interdiffusion and possible phase separation. An optimum exists near a 70:30 PA6:PCL core-to-shell ratio.

This results in a $G_{I C}$ of $650 \pm 50 \mathrm{~J} \mathrm{~m}^{-2}$ (ca. $+60 \%$ vs. virgin material) and a $G_{I I c}$ of $3160 \pm 35 \mathrm{~J} \mathrm{~m}^{-2}$ (also ca. $+60 \%$ vs. virgin material).

For PCL-based (coaxial) nanofibres, the advantages of both methods can be summarized as follows:

\begin{tabular}{llll}
\hline Method & Advantage & Considerations & Result \\
\hline 2-step & Single component & Working window requires a & $G_{I C}+60 \%$ \\
curing & nanofibres & relatively long curing step at $T<$ & $G_{I I c}+65 \%$ \\
profile & & $T_{m, P C L}$ & \\
\hline Coaxial & Freedom in core & Requires optimizing coaxial & $G_{I C}+60 \%$ \\
nanofibres & polymer type; & electrospinning; & $G_{I I c}+60 \%$ \\
& Direct and relatively & Curing at elevated temperature & \\
& fast cure possible & $T>T_{m, P C L}$ required & \\
\hline
\end{tabular}

\section{Acknowledgements}

L.D. and K.D.C. gratefully acknowledge financial support from the Special Research Fund (BOF) Ghent University (BOF 13/24J/020, BOF BAS and BOF.PDO.2015.0028.01).

\section{Supplementary information}

Supplementary information available: pictures of delamination test setups, loaddisplacement curves and delamination resistance-delamination growth curves from the delamination experiments. 


\section{References}

[1] R. Palazzetti, A. Zucchelli, Electrospun nanofibers as reinforcement for composite laminates materials - A review, Compos. Struct. 182 (2017) 711-727. doi:10.1016/J.COMPSTRUCT.2017.09.021.

[2] L. Daelemans, S. van der Heijden, I. De Baere, H. Rahier, W. Van Paepegem, K. De Clerck, Improved fatigue delamination behaviour of composite laminates with electrospun thermoplastic nanofibrous interleaves using the Central Cut-Ply method, Compos. Part A Appl. Sci. Manuf. 94 (2017) 10-20. doi:10.1016/j.compositesa.2016.12.004.

[3] L. Daelemans, A. Cohades, T. Meireman, J. Beckx, S. Spronk, M. Kersemans, I. De Baere, H. Rahier, V. Michaud, W. Van Paepegem, K. De Clerck, Electrospun nanofibrous interleaves for improved low velocity impact resistance of glass fibre reinforced composite laminates, 141 (2018) 170-184. http://www.sciencedirect.com/science/article/pii/S0264127517311590 (accessed January 17, 2018).

[4] B. De Schoenmaker, S. Van der Heijden, I. De Baere, W. Van Paepegem, K. De Clerck, Effect of electrospun polyamide 6 nanofibres on the mechanical properties of a glass fibre/epoxy composite, Polym. Test. 32 (2013) 1495-1501. doi:10.1016/j.polymertesting.2013.09.015.

[5] S. van der Heijden, L. Daelemans, B. De Schoenmaker, I. De Baere, H. Rahier, W. Van Paepegem, K. De Clerck, Interlaminar toughening of resin transfer moulded glass fibre epoxy laminates by polycaprolactone electrospun nanofibres, Compos. Sci. Technol. 104 (2014) 66-73. doi:10.1016/j.compscitech.2014.09.005.

[6] H. Yademellat, A. Nikbakht, H. Saghafi, M. Sadighi, Experimental and numerical investigation of low velocity impact on electrospun nanofiber modified composite laminates, Compos. Struct. 200 (2018) 507-514. http://linkinghub.elsevier.com/retrieve/pii/S0263822317343222 (accessed June 1, 2018).

[7] S. van der Heijden, L. Daelemans, T. Meireman, I. De Baere, H. Rahier, W. Van Paepegem, K. De Clerck, Interlaminar toughening of resin transfer molded laminates by electrospun polycaprolactone structures: Effect of the interleave morphology, Compos. Sci. Technol. 136 (2016) 10-17. doi:10.1016/j.compscitech.2016.09.024.

[8] L. Daelemans, S. van der Heijden, I. De Baere, H. Rahier, W. Van Paepegem, K. De Clerck, Nanofibre bridging as a toughening mechanism in carbon/epoxy composite laminates interleaved with electrospun polyamide nanofibrous veils, Compos. Sci. Technol. 117 (2015) 244-256. doi:10.1016/j.compscitech.2015.06.021.

[9] S. Hamer, H. Leibovich, A. Green, R. Avrahami, E. Zussman, A. Siegmann, D. Sherman, Mode I and Mode II fracture energy of MWCNT reinforced nanofibrilmats interleaved carbon/epoxy laminates, Compos. Sci. Technol. 90 (2014) 48-56. doi:10.1016/j.compscitech.2013.10.013.

[10] Resin-soluble thermoplastic veil for composite materials, (2014). http://www.google.com/patents/US8703630 (accessed August 20, 2015).

[11] L. Daelemans, S. van der Heijden, I. De Baere, H. Rahier, W. Van Paepegem, K. De Clerck, Using aligned nanofibres for identifying the toughening micromechanisms in nanofibre interleaved laminates, Compos. Sci. Technol. 124 (2016) 17-26. doi:10.1016/j.compscitech.2015.11.021.

[12] G.W. Beckermann, K.L. Pickering, Mode I and Mode II interlaminar fracture toughness of composite laminates interleaved with electrospun nanofibre veils, Compos. Part A Appl. Sci. Manuf. 72 (2015) 11-21. doi:10.1016/j.compositesa.2015.01.028.

[13] B. Beylergil, M. Tanoğlu, E. Aktaş, Enhancement of interlaminar fracture toughness of carbon fiberepoxy composites using polyamide-6,6 electrospun nanofibers, J. Appl. Polym. Sci. 134 (2017) 45244. doi:10.1002/app.45244.

[14] R.E. Neisiany, S.N. Khorasani, M. Naeimirad, J.K.Y. Lee, S. Ramakrishna, Improving Mechanical Properties of Carbon/Epoxy Composite by Incorporating Functionalized Electrospun Polyacrylonitrile Nanofibers, Macromol. Mater. Eng. 302 (2017) 1600551. doi:10.1002/mame.201600551. 
[15] B. Beylergil, M. Tanoğlu, E. Aktaş, Modification of Carbon Fibre/Epoxy Composites by Polyvinyl Alcohol (PVA) Based Electrospun Nanofibres, Adv. Compos. Lett. 25 (2016) 096369351602500. doi:10.1177/096369351602500303.

[16] L. Daelemans, S. van der Heijden, I. De Baere, H. Rahier, W. Van Paepegem, K. De Clerck, Damage resistant composites using electrospun nanofibers: a multiscale analysis of the toughening mechanisms., ACS Appl. Mater. Interfaces. 8 (2016). doi:10.1021/acsami.6b02247.

[17] K. Bilge, S. Venkataraman, Y.Z. Menceloglu, M. Papila, Global and local nanofibrous interlayer toughened composites for higher in-plane strength, Compos. Part A Appl. Sci. Manuf. 58 (2014) 7376. doi:10.1016/j.compositesa.2013.12.001.

[18] E. Özden-Yenigün, K. Bilge, E. Sünbüloğlu, E. Bozdağ, M. Papila, High strain rate response of nanofiber interlayered structural composites, Compos. Struct. 168 (2017) 47-55. doi:10.1016/j.compstruct.2017.02.007.

[19] K. Bilge, E. Ozden-Yenigun, E. Simsek, Y.Z. Menceloglu, M. Papila, Structural composites hybridized with epoxy compatible polymer/MWCNT nanofibrous interlayers, Compos. Sci. Technol. 72 (2012) 1639-1645. doi:10.1016/j.compscitech.2012.07.005.

[20] K. Bilge, Y. Yorulmaz, F. Javanshour, A. Ürkmez, B. Yılmaz, E. Şimşek, M. Papila, Synergistic role of in-situ crosslinkable electrospun nanofiber/epoxy nanocomposite interlayers for superior laminated composites, Compos. Sci. Technol. 151 (2017) 310-316. doi:10.1016/J.COMPSCITECH.2017.08.029.

[21] L. Daelemans, W. Van Paepegem, D.R. D'hooge, K. De Clerck, Excellent Nanofiber Adhesion for Hybrid Polymer Materials with High Toughness Based on Matrix Interdiffusion During Chemical Conversion, Adv. Funct. Mater. (2018) 1807434. doi:10.1002/adfm.201807434.

[22] S. De Vrieze, B. De Schoenmaker, Ö. Ceylan, J. Depuydt, L. Van Landuyt, H. Rahier, G. Van Assche, K. De Clerck, Morphologic study of steady state electrospun polyamide 6 nanofibres, J. Appl. Polym. Sci. 119 (2011) 2984-2990. doi:10.1002/app.33036.

[23] L. Van der Schueren, B. De Schoenmaker, Ö.I. Kalaoglu, K. De Clerck, An alternative solvent system for the steady state electrospinning of polycaprolactone, Eur. Polym. J. 47 (2011) 1256-1263. doi:10.1016/j.eurpolymj.2011.02.025.

[24] A. Arrese, N. Carbajal, G. Vargas, F. Mujika, A new method for determining mode II R-curve by the End-Notched Flexure test, Eng. Fract. Mech. 77 (2010) 51-70. doi:10.1016/j.engfracmech.2009.09.008.

[25] A. Cohades, L. Daelemans, C. Ward, T. Meireman, W. Van Paepegem, K. De Clerck, V. Michaud, Size limitations on achieving tough and healable fibre reinforced composites through the use of thermoplastic nanofibres, Compos. Part A Appl. Sci. Manuf. 112 (2018) 485-495. doi:10.1016/J.COMPOSITESA.2018.07.002.

[26] G.-F. Yu, X. Yan, M. Yu, M.-Y. Jia, W. Pan, X.-X. He, W.-P. Han, Z.-M. Zhang, L.-M. Yu, Y.-Z. Long, Patterned, highly stretchable and conductive nanofibrous PANI/PVDF strain sensors based on electrospinning and in situ polymerization, Nanoscale. 8 (2016) 2944-2950. doi:10.1039/C5NR08618C.

[27] P. Li, Y. Li, B. Ying, M. Yang, Electrospun nanofibers of polymer composite as a promising humidity sensitive material, Sensors Actuators B Chem. 141 (2009) 390-395.

doi:10.1016/J.SNB.2009.07.006. 